\title{
Sociedad civil y ciudadanía: pistas para su comprensión y fortalecimiento: estudio de casos múltiples
}

\author{
Ana María Alvarez Rojas* , Ana María Contreras Duarte*, M. Daniela Sánchez Stürmer*
}

\begin{abstract}
Resumen
Este artículo presenta los resultados de una investigación llevada a cabo por el Departamento de Trabajo Social de la UCSH en el período 2003-2005. En ella, se aborda la evolución de tres situaciones de interés público seleccionadas para la realización del estudio, a saber, el conflicto generado en torno al Relleno Sanitario Santa Marta -Región Metropolitana- la crisis de la Salud Pública y el debate previo a la promulgación de la Ley de Divorcio. La reconstrucción de estas situaciones se realizó con el objeto de posibilitarnos el reconocimiento de actores de la sociedad civil-individuos y/u organizaciones- que asumieron un rol activo en el conflicto, evidenciado por la articulación y difusión de un discurso público respecto al tema. Luego, se buscó profundizar en esta información mediante la recolección del discurso de distintos actores de la sociedad civil vinculados a las tres situaciones de interés público. Los criterios de selección de estos informantes fueron: que se tratara de actores estratégicos en términos de representar una posición definida en la situación (la mayoría de los entrevistados aparecen mencionados en las fuentes consultadas) y dos, que tuvieran voluntad y disposición a participar en la investigación. Ello, con el propósito de reconstruir primero, los máximos éticos (A. Cortina) contenidos en sus posiciones, para luego, a partir de la caracterización de esos máximos, buscar elementos comunes (mínimos) que nos permitieran reflexionar sobre las posibilidades de constitución de una ética cívica.
\end{abstract}

\section{Palabras clave}

Ciudadanía, Sociedad Civil, Máximos Éticos, Mínimos Éticos, Ética Cívica, Interés Público, Generaciones de Derechos, Democracia, Participación.

\section{Abstract \\ CIVIL SOCIETY AND CITIZENSHIP: CLUES FOR THEIR UNDERSTANDING AND FORTIFICATION:} MULTIPLE-CASE STUDIES

This article displays the results of an investigation carried out by the Social Work Department of UCSH between the years 2003 -2005. In this research, the evolution of three situations of public interest selected for the accomplishment of the study is approached, that is to say, the conflict generated around the Santa Marta Sanitary Rubbish Damp - Metropolitan Region - the crisis of the Public Health and the previous debate to the promulgation of the Law of Divorce. The reconstruction of these situations was made with the intention of making possible the recognition to us of actors of the civil society - individual and organizations - that assumed an active roll in the conflict, demonstrated by the joint and diffusion of a public speech with respect to the subject. Soon, it was necessary to deepen in this information by means of the recollection of the speech of different actors from the civil society tied to the three situations of public interest. The selection criteria of these informants were: one, those strategic actors, in terms of representing a position defined in the situation (most of the interviewed people appeared to be mentioned in the consulted sources) and two, that those actors had will and disposition to participate in the investigation. Thus, in order to reconstruct the first, maximum ethical (A. Cortina) contents in their positions, and then, from the characterization of those maximums, look for common elements (minimum) that allowed us to reflect on the possibilities of the constitution of a civic ethics.

\section{Key words}

Citizenship, maximum ethics, minimum ethics, civic ethics, public interest, rights generations, democracy, participation.

* Académica Departamento de Trabajo Social, Universidad Católica Cardenal Raúl Silva Henríquez.

Contactos: amalvare@ucsh.cl; acontrer@ucsh.cl; dsanchez@ucsh.cl.

\section{Presentación}

工 os máximos éticos son lo que Adela Cortina describe como las aspiraciones de felicidad o bienestar individual que cristalizan proyectos biográficos de autorrealización, encarnados en sistemas de creencias como las religiones, las ideologías políticas u otros. Estos meta relatos jugarían un papel esencial como modelos de referencia o de vida. En esta perspectiva, la ética cívica podría concebirse como una "conquista" de las sociedades democráticas y pluralistas respecto de aquello que debe ser reconocido como deseado y positivo para todos y cada uno de sus ciudadanos, más allá de sus naturales diferencias. Y que éstos, al mismo tiempo, se comprometen a respetar y defender (Cortina, 1998). Es, a partir de este marco general, que fueron analizados los discursos de los entrevistados, no como un parámetro ético normativo al que debían acordarse, sino, más bien, como un referente para establecer la posición de los 
hablantes respecto del mismo. Ello posibilitaría la reflexión en torno a las condiciones de posibilidad de la constitución de una ética cívica.

Dentro de los principales objetivos y de las preguntas de investigación que se planteó este estudio, se encontraba la posibilidad de reconstruir los máximos éticos sobre los cuales se sustentan discursos respecto de tres situaciones de interés público presentes en la agenda pública entre los años 2003 y 2004, en Chile. Ello significó examinar en profundidad la información recogida, en la perspectiva de reconocer los referentes ideales que subyacen a la posición de los actores ${ }^{1}$. ¿Qué piensan sobre lo que debe o no debe implicar el cuidado y protección del medio ambiente, en el caso de los vinculados al conflicto en torno al Relleno Sanitario Santa Mar-

1 Respecto al conflicto suscitado en torno a la instalación del Relleno Sanitario Santa Marta, se buscó un representante de los propietarios de Viñas del Valle del Maipo (organización social de base), un profesional que representara los intereses de los vecinos que se opusieron a la instalación del Relleno Sanitario, un dirigente de la Red Nacional de Acción Ecológica (RENACE) y la responsable del área ambiental de la Fundación TERRAM. En relación con la situación que representa la segunda generación de derechos, se realizaron entrevistas a representantes de organizaciones gremiales de trabajadores de la salud CONFENATS y de una organización no gubernamental que realiza educación popular en salud, EPES, a fin de recoger sus opiniones sobre el conflicto suscitado en torno a la crisis de la Salud Pública. Del mismo modo, se entrevistó a Rodrigo castro, encargado de temas sociales del Instituto Libertad y Desarrollo y se estableció un contacto con un dirigente gremial del Colegio Médico de Chile, el que no prosperó. En cuanto al divorcio, situación representativa de la Tercera Generación de Derechos, sólo nos fue posible recoger el punto de vista del representante de la organización "Acción Familia", colectividad que asumió una posición crítica frente al proyecto de Ley, lo hizo público y desplegó acciones en conformidad a sus objetivos. En cuanto a la posibilidad de recoger el discurso de representantes de las iglesias católica y evangélica y de otras organizaciones sociales y/o no gubernamentales que sustentaran un discurso a favor o contrario al divorcio, si bien se realizaron contactos, éstos no produjeron resultados. En el caso de este conflicto, se observó la inexistencia de discursos oficiales por parte de los organismos referidos. Se encontraron artículos dispersos y seminarios realizados con ocasión del advenimiento de la Ley, que no se tradujeron en el desarrollo de un pensamiento. Ello tornó más dificultosa la tarea de contactar informantes dispuestos a colaborar con el estudio. ta? ¿Debe la protección del medio ambiente -en el entendido que ésta se relaciona estrechamente con la cuestión de la salud pública de la población- supeditarse a intereses de otra naturaleza? ¿Cuáles son los límites de la libertad económica? ¿Qué ejes articuladores centrales es posible reconocer en cada propuesta? ¿Qué perspectivas de Estado subyacen a las posiciones que consideran la Salud como un Derecho Universal, el que debe, además, ser garantizado por el Estado? ¿Cómo se entiende el Derecho a la Salud en perspectivas que reivindican el valor de la libertad de elección? ¿Es dable la posición de la Iglesia frente a la importancia que atribuyen al reconocimiento legal de la indisolubilidad del matrimonio en el contexto de una sociedad pluralista? Estas y otras interrogantes relacionadas con la especificidad de cada conflicto intentamos responder en este artículo.

La reconstrucción de los máximos éticos se hizo para cada situación de interés público en función de la cantidad y especificidad de discursos que fue posible pesquisar en cada ejemplo, reconociendo y describiendo también la manera cómo el Estado se posesionaba frente al tema en cuanto a favorecer 0 dificultar condiciones para la construcción de una ética cívica en torno a estos casos. Para organizar la información recopilada a través de fuentes secundarias -que posibilitó la redacción de tres informes donde se describía la trayectoria histórica de los conflictos-se procedió a la lectura reiterada de este material. Teniendo como técnica de ordenamiento y análisis de la información el análisis categorial con categorías predefinidas, las que se desprendieron directamente de las preguntas y objetivos de investigación. Estas categorías corresponden a los componentes de la denominada Etica Cívica o Etica de la Sociedad Civil (Derechos, Valores y Actitud Dialógica) y que se articulan de manera singular en torno a cada una de las llamadas Tres Generaciones de Derechos; a saber, Civiles y Políticos (primera generación), Económicos, Sociales y Culturales (segunda generación) y Medio Ambientales y a la Paz (tercera generación) en el entendido de que una sociedad democrática y pluralista ha obtenido 
consensos básicos respecto de lo que aspira en relación a cada una de estas generaciones.

Para "rastrear" estos componentes de la Etica Cívica, se procedió a la confección de una pauta de lectura que operacionaliza su sentido, a fin de poder identificarlos con facilidad en el discurso de los actores del conflicto y que reproducimos más adelante. En tanto se trabajó a partir de categorías generales, se tuvo la expectativa de encontrar sub categorías como resultado de un análisis más afinado, situación de la que damos cuenta en los cuadros que sintetizan la información y que no reproducimos por razones obvias en este artículo.

Los datos obtenidos mediante las entrevistas semi estructuradas fueron tratados de la misma manera y se hará referencia a las similitudes o disparidades encontradas en ambos materiales una vez que se proceda a la reconstrucción de los máximos.

\section{Relleno sanitario Santa Marta}

La Sustentabilidad del Desarrollo pareciera ser la utopía que condensa la aspiración compartida por todos los representantes de la sociedad civil que alzan su voz frente al conflicto suscitado en torno al Relleno Sanitario Santa Marta; ideal que refleja al conjunto de individuos y organizaciones que rechazan su instalación, siendo el sello característico de casi todos los discursos la importancia de cautelar y proteger el medio ambiente. Este objetivo aparece gravemente vulnerado por el Gobierno chileno en la persona del Intendente de la época, Marcelo Trivelli. Entre estas organizaciones, se destacan la Fundación Terram, la Red de Acción Ecológica (RENACE) - organismo que articula un conjunto de organizaciones ecológicas y medio ambientales - los representantes de la propuesta Chile Sustentable, la Asociación de Viñateros del Valle del Maipo, más otros actores, como el abogado defensor de los intereses de los vecinos de Maipú y algunos académicos de Universidades y Centros de Investigación dedicados al tema, que se manifestaron frente al conflicto. Es posible reconocer la presencia de estos actores ya en el análisis de las fuentes secundarias, a partir de las cuales se pudo realizar la reconstrucción sumaria de los casos, siendo los representantes de la RED RENACE, la Fundación TERRAM, el abogado defensor de los intereses de los vecinos del Relleno Sanitario y un representante de la Asociación de Viñateros, escogidos como informantes clave para la profundización de los temas.

En el discurso de cada uno de estos tres actores, es posible reconocer la convicción de que los objetivos de crecimiento económico a los que se encuentran supeditados, casi sin excepción, todos los modelos de desarrollo de los países que forman parte del sistema de economía transnacionalizada, deben quedar subordinados al cuidado y al respeto por el patrimonio ecológico y medio ambiental de una nación y de la tierra. Es así cómo sostienen:

- $\quad$ "Es un deber proteger este medio ambiente que ha sido absolutamente deteriorado por la forma irracional del hombre de explotar los recursos naturales”2.

- (...) "en nuestra economía prima el interés por el lucro. Cuando tú tienes un basural mal llevado afecta no solo el medioambiente, sino también la salud y la economía, pues daña la producción agrícola, baja el precio de los terrenos...”3

- (...) era realmente un basural que no tenía unas características técnicas que evitaran cualquier problema futuro, tanto ambiental como de riesgo a la salud de las personas”. ${ }^{4}$

Estas posiciones, como indicamos más arriba, pueden ser resumidas en la propuesta del Desarrollo Sustentable, perspectiva que, aunque todavía en proceso de construcción, se fundamenta en prin-

2 Representante de RENACE.

3 Abogado defensor de la comunidad afectada por el Relleno Sanitario Santa Marta.

4 Representante de la Asociación de Agricultores del Valle del Maipo. 
cipios que sostienen la importancia de la relación entre todos los componentes o dimensiones del desarrollo, privilegiando, en razón de sus fundamentos éticos, los aspectos relacionados con la manutención y preservación de la salud, bienestar y calidad de vida de la población y el resguardo de los eco sistemas y del medio ambiente. Ello supone, como premisa, que todas las decisiones y acciones que se emprendan en este dominio deben quedar subordinadas a objetivos eco sociales y eco ambientales, aunque se limiten o restrinjan las posibilidades de crecimiento económico.

Esta aspiración se ha ido convirtiendo progresivamente en una demanda inscrita en lo que Montagut denomina "El bienestar social internacional", como un potencial campo de estudio en la medida que los Estados se muestran insuficientes en sus posibilidades de poder abarcar de manera adecuada las problemáticas que actualmente plantea la globalización. Por ejemplo, para entender los problemas ambientales que existen hoy en día en muchos países y los conflictos sociales derivados de ellos, se requiere recurrir a una estrategia idónea que permita poner en perspectiva el modo en que las fuerzas externas a un territorio o país modifican parte de su funcionamiento interno. En este sentido, vemos que, detrás de un problema como el suscitado en torno al Relleno Santa Marta, existe una complejidad que obliga a su descomposición en diferentes niveles, a modo de asir en forma más precisa las contradicciones que allí se despliegan.

La exacerbación de la dimensión económica del desarrollo, es decir, el crecimiento, sería para todos, sin excepción, la responsable del deterioro medio ambiental, a lo que se suman bajísimos niveles de conciencia ciudadana respecto al tema y una institucionalidad débil en esta materia. La protección legal e institucional efectiva pareciera ser, en consecuencia, una de las deudas pendientes de los gobiernos de la concertación, los cuales, desde su advenimiento, proclamaron el desarrollo sustentable como marco de su política ambiental. Como indica Fuentealba: "La política Ambiental chilena introduce el concepto de sustentabilidad al establecer en nuestra legislación 'el derecho a vivir en un medio ambiente libre de contaminación, la protección del medio ambiente, la preservación de la naturaleza y la conservación del patrimonio ambiental'” (art. 2 Ley N ${ }^{a}$ 19.300) (Fuentealba y Celis: 2003: 33). Se declara, además, que la política ambiental tiene, como fin último, la calidad de vida de todos los chilenos, sin perder de vista las necesidades de las generaciones futuras. En la percepción de los distintos actores involucrados en este conflicto, las graves deficiencias de las que adolece la institucionalidad y la gestión ambiental le restan credibilidad.

- la ley en Chile está mal hecha, contiene muchos sentidos perversos... leyes que son francamente vergonzosas (...)."

- "la movilización es muy buena pero tiene que haber un nexo legal, sirve para poner el problema en el tapete, eso solo va a tener un efecto positivo si se traduce en sentencia, en resoluciones judiciales (...)”

- consiguieron cambiar la ley $\mathrm{N}^{0} 3133$ lo que ha tenido y va a tener consecuencias funestas para el medio ambiente." ${ }^{5}$

- "la institucionalidad ambiental está colapsada, perdió el norte por el cual se formó”. ${ }^{6}$

- “necesitamos una nueva institucionalidad ambiental, autónoma, con capacidad de fiscalización, con poder de decisiones y con objetivos a largo plazo $(. . .)^{7}$

Para Roberto Güimaraes, "no debe sorprender la ausencia de argumento ecológico en el pensamiento sociológico, político y económico tradicional. No sorprende tampoco la disfuncionalidad de la mayoría de las instituciones políticas contem-

5 Abogado defensor de los intereses de la comunidad afectada.

6 Representante de RENACE.

7 Representante Fundación TERRAM. 
poráneas para afrontar desafíos de la transición, creadas en un mundo de abundancia económica, estas se revelan incapaces de responder al reto de la escasez ecológica y ambiental”(Güimaraes, 2003, Pág.12).

Si bien la constatación de la hegemonía de una racionalidad estratégica vinculada a la producción de riqueza y la falta de un consenso ético fuerte, articulado sobre la idea de la sostenibilidad, explican que se homologue crecimiento económico a desarrollo social y político, no resultan argumentos suficientes al momento de intentar comprender los motivos de esta opción. Cambiar el actual sistema supondría, entre otras cosas, modificar sustancialmente la perspectiva positivista que ha caracterizado la manera de entender este proceso y comprometerse en acciones concretas donde se manifiesten nuevas maneras de establecer las relaciones entre hombre y naturaleza.

- “Tuvimos un seminario en Mendoza, Argentina, y los temas son los mismos, porque los actores son las mismas multinacionales o sea tú estás peleando con una multinacional aquí porque te está depredando, talando, por decirte el roble, ese mismo ejemplo, y resulta que en Brasil son los mismos que están dejando al escoba, en el Amazonas, todos tenemos aquí problemas, Argentina, Chile con una compañía minera que está explotando el cobre, que están tirando los relaves al mar, que están contaminando las playas de Chañaral, que en esto que el otro y resulta que, en Colombia, en Perú, es la misma empresa. Entonces, los problemas yo diría que son regionales, en el caso de Chile".

- "Nos corresponde a nosotros como organización, enfrentamos el tema de la participación ciudadana en los proyectos, que es una situación discriminatoria en la ley,... espero que eso cambie ahora, con las modificaciones a la ley 19.300, que tiene que ver con el tema de la participación en igualdad de condiciones...”
Esta versión del desarrollo, heredera del racionalismo y del empirismo y que tiende a la fragmentación, habría sido inducida por el proyecto racionalista dominante en la explicación de "lo social” durante los siglos XIX y XX, el que, dentro de sus premisas básicas, sostiene la necesidad de descomponer para conocer. La comprensión del "todo" vendría dada por la síntesis de lo fragmentado, que nos daría la ilusión de una explicación “totalizadora”. Así, seguimos hablando de desarrollo cuando en los hechos estamos enfatizando una sola de sus dimensiones: el crecimiento. Asimismo, la separación entre quien conoce y quien es "conocido" o, en otras palabras, quien interviene y quien es objeto de esta intervención, induce la configuración de una situación donde los afectados y quienes toman las decisiones, pertenecen a "universos distintos", con el riesgo que ello supone de asumir al otro como un objeto (pasivo, deficitario) y el cuestionamiento de esta conducta como atentatoria a los principios democráticos de igualdad y participación, expresados en la forma que adquiere la relación racionalidad político/técnica, racionalidad comunitaria, en este caso.

Como observamos, estos elementos característicos de la racionalidad descrita se hacen extensivos al campo de la acción política, lo que explica, en parte, la debilidad de la sociedad civil para contrabalancear la fuerza depredadora que asume, en la realidad, el objetivo de maximización de la riqueza asociado al modelo de crecimiento. De este modo, los entrevistados reconocen, en el conflicto del Relleno Sanitario, un predominio de intereses económicos de corto plazo por sobre el respeto al medio ambiente y a la salud de la población, lo que se evidencia en distintos aspectos de la propuesta tales como su localización, el breve período preparatorio de su puesta en marcha, incumplimiento de ciertas exigencias técnicas, negación o minimización de los efectos que la instalación del Relleno tendría en la producción agrícola, el precio de los terrenos, entre otros.

Se suma a ello la debilidad de la ciudadanía para contrarrestar la fuerza de una decisión, en la que, a

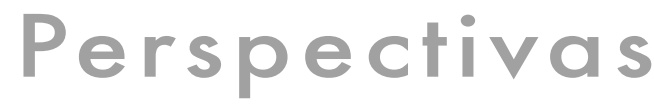


juicio de la mayoría de los entrevistados, el Estado aparece alineado con los intereses del capital.

- (...) “ese proyecto jamás debió haberse aprobado, entonces por supuesto que uno piensa después de la aprobación que había otro tipo de intereses: gente metida detrás del proyecto, que logró a través del lobby que se aprobara...”.

- CLo que pasa en el asunto de Santa Marta y Rinconada de Maipú, es que el proceso de licitación fue turbio, se cambiaron las bases técnicas, al final la solución fue por plata y no por condiciones técnicas....”

También se observa, en estas declaraciones, una aspiración común por lograr mayor conciencia ambiental de la sociedad chilena en su conjunto. Se denuncian prácticas cotidianas vinculadas al consumo, uso de sustancias tóxicas, mal manejo de residuos que revelan la ausencia de convicción sobre la necesidad de cuidado ambiental:

- "Nuestro planeta y nosotros estamos en peligro de extinción, debiéramos nosotros mismos por las irresponsabilidades que hemos hecho, entre ellas la destrucción de nuestra naturaleza, tomar conciencia”.

- “Un tema importante es hacer conciencia, hablar con los dirigentes, hacemos reuniones con los dirigentes, seminarios, acciones en la plaza, cosa que la gente vaya sintiendo que el problema es suyo, que todo el mundo vaya apoyando y no dejemos solamente a la comunidad enfrentada con el tema”. ${ }^{8}$

No obstante, la generación de esta conciencia ambiental es una tarea que demanda acuerdos sociales previos sobre sus fundamentos éticos y sobre los mecanismos institucionales y de otra naturaleza, necesarios para impulsarla. Siguiendo a Escobar, asumiendo la importancia que reviste la toma de

8 Representante de Fundación TERRAM conciencia de los ciudadanos "es insuficiente (...) pues $(. .$.$) se requiere de un abordaje plural, inter-$ sectorial y transdisciplinario, para construir una red social que exprese la complejidad de criterios presentes en la sociedad civil y en la iniciativa social organizada."

Esta complejidad se pone de relieve en las tensiones a las que aluden los entrevistados que comparten el máximo ético de la sustentabilidad del desarrollo, ya que se trata de objetivos de transformación a largo plazo, y cuya desestimación significa seguir generando daño medioambiental y sobre explotación de los recursos.

Igualmente, sostiene Güimaraes, a generaciones de sujetos para quienes los problemas más básicos de la vida no estén resueltos les resulta imposible poder pensar siquiera problemáticas que no se vinculan directamente con lo que ellos sufren a diario. Es más, estima que una generación en que predomine la pobreza, la desigualdad y la exclusión no sólo profundiza la degradación ambiental y el uso degradante de los recursos sino que, además, los individuos se alienan y pierden la identidad configurando un escenario que hace dudar acerca de "la promesa de una generación futura” (Güimaraes, op. cit. 2004).

- “...como hemos ido envenenando el medio ambiente, como hemos ido talando indiscriminadamente, como hemos ido matando animales, entonces todo eso va produciendo un gran daño en el planeta y eso como que la gente empieza a tomar conciencia” ${ }^{10}$.

- $\quad$ "Chile depende fundamentalmente de los recursos naturales que tiene, esos son los que nos dan todas las ganancias; las exportaciones, entonces si no cuidamos ese patrimonio a la larga Chile se va a quedar con nada" ${ }^{11}$.

9 Escobar Juan, "Modelo económico, sustentabilidad y consumo", Revista perspectivas №1 1,2002.

10 Fundación TERRAM

11 Asociación de Viñateros. 
- "Chile tiene una inmadurez muy grande en lo que es la conciencia ambiental”. ${ }^{12}$

El acento de este máximo pareciera, entonces, estar en la utopía de un nuevo estilo de desarrollo ambiental que considere, de otro modo, el acceso y uso de los recursos naturales y la preservación de la biodiversidad. No obstante, cuestiones de equidad social asociadas a la legitimidad de exigir a los excluidos “conciencia ambiental” parecieran no ser todavía objeto de discusión colectiva, incluso en quienes asumen como ideal este paradigma emergente.

- "En este contexto, el problema no es solo ambiental, sino político y económico, ya que, existiendo terrenos apropiados, no se utilizan, porque a algunas comunas no les conviene dicha localización”. ${ }^{13}$

- “La Asociación Viñas de Chile, presidida por Rafael Guilisasti, manifestó un completo rechazo a dicha instalación en Lonquén, argumentando que su construcción contaminaría las aguas, el aire y el suelo". ${ }^{14}$

Pensar en términos de sustentabilidad implica, según los entrevistados, adoptar una mirada compleja donde todas las dimensiones del funcionamiento de una sociedad deben estar interrelacionadas y orientarse por una racionalidad que permita prever el efecto que tendrá una medida, cualquiera sea su carácter, sobre el conjunto de la naturaleza y de los individuos. Avanzar hacia una sociedad sustentable supondría la existencia de una conciencia ambiental centrada en la interrelación de todas las formas de vida y los procesos ecológicos, comprendiendo cuáles son los valores culturales y sociales implicados en dicho proceso, es decir, los mínimos requeridos en este campo. Incluso, si no se conocieran bien los efectos de una intervención sobre

12 Fundación TERRAM.

13 Académicos U. de Chile.

14 Representante Asociación de Viñateros del Valle del Maipú. los recursos naturales y el medio ambiente, la ONU recomienda abstenerse de operar apelando a lo que se denomina "el principio precautorio". No tener en consideración estos elementos significa asumir que habría algunas dimensiones del desarrollo que serían "más importantes que otras” y en cuya definición y priorización la ciudadanía no ha tenido ninguna participación, menos los más pobres.

- $\quad$ "Si yo tengo una empresa, voy a fabricar algo mejor, en menos tiempo, de mejor calidad, con un costo menor si la persona que me hace el trabajo, primero sabe más, segundo entiende mejor, tercero, ve el futuro mejor, y todo eso depende de la educación y la cultura y eso yo puedo hacer llegar a otro mercado, con este producto y me lo van a elegir a mí, si tenemos a esa persona ${ }^{15}$ ".

En este conflicto se manifiesta, como en ningún otro, la idea de una ciudadanía planetaria. Es decir, una actitud compartida con relación al reconocimiento de esta interdependencia entre subsistemas, y a lo imperativo que resulta que no sean sólo los Estados quienes hagan esta constatación, sino, también, todos los ciudadanos. Y que ello se constituya, en lo posible, en una fuerza globalizada, así como "globalizado" es el carácter del deterioro que denuncian. Cabe subrayar que todos, sin excepción, destacan que el respeto por el medio ambiente y los recursos no se obtiene sólo mediante un sistema democrático formal, sino que requiere la construcción y el esfuerzo continuo de instituciones democráticas específicas, capaces de inducir un proceso de desarrollo socialmente equitativo y ecológicamente sustentable, manteniendo el control y los límites políticos que establecen relaciones de mercado desiguales y desestabilizantes (Rattner, 2002).

- “(...) sólo genera conflictos ambientales en donde la ciudadanía no tiene derecho ni a voz ni a voto. Señala, además, que los vecinos del sector han sido sistemáticamente ignorados

15 Edmundo Silva, Representante Asociación de Viñateros del valle del Maipo.

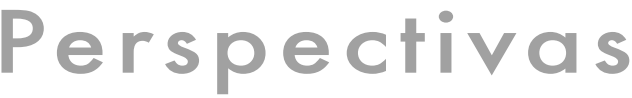


cuando la comunidad denunció las primeras filtraciones visibles".

- “Aquí se aprobó una estructura ambiental del país en que la misma autoridad es la que aprueba, certifica, fiscaliza y la que da recursos o los quita..”

- "Una democracia tiene que ser más participativa si no todo lo otro es un engaño; los que tienen que moverse aquí son las personas (...)"

- Hay muy pocos espacios para la ciudadanía $y$, en general, estos espacios no son resolutivos". ${ }^{16}$

Las declaraciones de los opositores a la instalación del Relleno Sanitario Santa Marta hacen patente la insuficiencia de las estructuras tradicionales de representación política frente a temas que afectan directamente la calidad de vida de los ciudadanos. Estos debieran, en consecuencia, contar a nivel local con instrumentos claros de participación para la defensa de sus derechos ambientales. Esta aspiración transversal de un mayor protagonismo ciudadano, reafirma lo planteado por J. Borja en términos de la necesidad de pasar de lo que denomina los “derechos simples" -donde se ubican las tres generaciones de derechos sobre las cuales trabajamos-a los “derechos complejos", es decir, una respuesta que contenga mayor universalidad, especificidad y densidad democrática que las conquistas relativas a las ya conocidas tres generaciones.

Ello, en el campo político, debiera traducirse en lo que se denomina, democracia deliberativa, que equivale a la posibilidad de los ciudadanos de tener mayor participación directa, control sobre la gestión pública, acceso a la información relativa a los gastos fiscales, consideración de sus opiniones para la toma de decisiones que afecten la vida colectiva, entre otros aspectos.

16 Representante de la Asociación de Agricultores del Valle del Maipo.
- $\quad$ "En opinión de los pobladores afectados, el cambio en esta denominación no sería más que un acuerdo o protocolo entre empresas encargadas de la administración y procesamiento de la basura y los políticos, pues no significaría la eliminación de los daños y perjuicios que acarrea el vertedero sobre el valor de sus propiedades, la calidad del aire y la salud de la población, entre otros aspectos”.

Lo anterior, supone que la posibilidad de salir de un conflicto como el descrito no se restrinja a las políticas sociales nacionales y centralizadas y, por lo tanto, a las formas clásicas de gestión de dichas políticas, sino al establecimiento de "políticas de proximidad" que consideren el contexto inmediato, las situaciones individuales, se apoyen en la cooperación social, en la prevención e inserción y que posean un carácter multidimensional e integral (Borja, op.cit: 2004).

- $\quad$ "No se modificaron los instrumentos de planificación territorial en la zona, ni tampoco las políticas regionales, de ahí que se estime que su calificación favorable obedece a razones extra ambientales.”

Se trata, en opinión del autor citado, de políticas "locales y localizadas” que establezcan una separación e, incluso, una confrontación con el sistema político nacional. Esta ruptura debería darse en tres aspectos: la cultura política, el sistema representativo y la conquista de competencias locales. Sin entrar a detallar qué significa cada uno de estos elementos, su integración activa supondría promover la autogestión y la autodeterminación local, incentivar la democracia deliberativa (y no solo la representativa) y que los sistemas políticos/legales sean fuertes y constituyan instrumentos eficaces para el ejercicio y protección de derechos ciudadanos (Borja, 2004).

- "Esto y la forma en que se aprobó el proyecto, generaron dudas respecto de los procedimientos, significando incluso la amenaza de una acusación constitucional contra el Intendente Trivelli”. 
En una línea argumentativa similar a la propuesta por Borja, Alguacil Gómez ${ }^{17}$ indica que la "tendencia a la pérdida de soberanía y al decaimiento del Estado-nación, que en la última etapa del proceso de construcción de la ciudadanía es el que tiene el monopolio sobre su definición, ha supuesto un freno al proceso permanente de construcción de la misma y nos lleva a pensar en otros ámbitos políticos y territoriales donde este proceso pueda continuar en su vertiente más activa. Sin ánimo de menospreciar los ámbitos supraestatales (y los estatales), donde debe proclamarse una defensa de la universalidad de los derechos de ciudadanía, parece que los nuevos retos de la ciudadanía se vuelven a discutir desde una doble perspectiva que tiene muchos puntos de vinculación: buscar una alternativa entre el liberalismo desregulador y el burocratismo estatista; y desarrollar la configuración de su base territorial” (Alguacil, Gópez, Julio: 2002:4).

Santa Marta no simbolizaría un simple conflicto ambiental, sino un desacuerdo socio político que pone de relieve la hegemonía de una manera de entender el orden de los factores en materia de desarrollo, donde, indudablemente, la racionalidad económica y política supraestatal y estatal, supeditada a la anterior, hacen prevalecer los intereses del capital por sobre otros aspectos, particularmente la posibilidad de la democracia deliberativa, la efectividad de los instrumentos de protección legal en materia medioambiental y la calidad de vida de la comunidad.

Ello reafirma lo que planteamos en el marco de referencia de este estudio en el sentido de subrayar la incapacidad de los Estados Nacionales, de proteger el medio ambiente y a los ciudadanos de los intereses de una economía a la cual someten sus decisiones. Sin embargo, sobre este punto, cabe hacer dos salvedades: los Estados Nacionales no pueden abandonar el rol que les compete en la generación de condiciones para el desarrollo endógeno y la protección del medio ambiente. Para ello, es preciso que la institucionalidad democrática

17 Madrid (España), marzo de 2002. http://habitat. aq.upm.es/boletin/n24/ajalg.html. pág. 4. funcione, permitiendo formas justas de distribución de recursos públicos y la definición de prioridades sociales.

Se hace manifiesto que en el conflicto del Relleno Sanitario se confrontan los intereses de la Sociedad Civil - representados en el gran máximo ético del desarrollo sustentable, compartiendo como "mínimos” más claramente reconocibles: un rechazo a la subordinación a la lógica estratégica del capital del resto de las esferas del funcionamiento social, junto con un fuerte énfasis en la participación ciudadana y en el ejercicio de la democracia directa - con los del Estado y del Mercado.

El Estado, contrariamente a lo planteado por Cortina respecto al papel que debiera jugar en la construcción de los mínimos éticos, no estaría, en consecuencia, contribuyendo con su actuación al fortalecimiento de mínimos de la sociedad civil activada en torno a este conflicto, pues no garantizaría a todos los "habitantes de su país" (...) condiciones básicas "en los distintos aspectos y ámbitos sociales requeridos para una convivencia pacífica, acogedora y acorde con la dignidad humana” (Cortina, op. cit, 1998).

El Gobierno de la Concertación aparece, según los entrevistados, fuertemente "coludido" con los intereses de las empresas que han asumido la responsabilidad de la gestión y mantenimiento de lo que se percibe fundamentalmente como "el negocio de la basura” por sobre los intereses de la ciudadanía. A partir de lo señalado, las movilizaciones sociales generadas en oposición a la instalación de rellenos sanitarios en determinados sectores del área metropolitana de Santiago, podrían significar una coyuntura propicia para el levantamiento de un debate en torno a la constitución de una ética cívica en nuestro país. De hecho, para Sabatini, estas movilizaciones serían de las pocas acciones colectivas emprendidas por los ciudadanos durante estos casi 13 años de transición democrática ${ }^{18}$. Oriol Nel-lo ${ }^{19}$ sostiene

18 Sabattini, Francisco, Wormald.... La Guerra de la basura... 19 Profesor de Geografía de la UAB y diputado de los Ciudadanos para el Cambio. Cataluña, Barcelona, España.

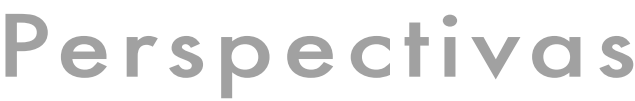


que los Vertederos constituyen un tipo de uso peri urbano que junto, con otros, tales como cárceles o centrales nucleares, suscitan el rechazo unánime de la población residente en el sector, quienes articulan su protesta en torno a la negativa de la instalación cercana a sus domicilios, pero no se oponen al sentido, a la opción o a las consecuencias medioambientales que implican algunas de éstas para el conjunto de una región. Estos conflictos se conocen con el nombre de conflictos NIMBY (del inglés “No en mi patio”) los cuales, a pesar de su carácter reactivo, monotemático, a- institucional y a veces a-político, contendrían un potencial transformador en la medida que pueden inscribirse en el marco de una reflexión global, pasando de un "Aquí no" a la participación en la búsqueda de soluciones. Si no es aquí ¿dónde? ¿cómo?, preguntas que posibilitarán sacar el conflicto de sus límites territoriales para constituirlo en una situación de interés general (Nel-lo, Oriol, 2004) y, por lo tanto, en la base para la constitución de una ética cívica con mayores niveles de formalización y, por ende, con más posibilidades de contrarrestar el peso de las decisiones de los otros actores involucrados en la situación.

\section{La salud y los máximos éticos: entre la universalidad del estado de bienestar y el individualismo de la elección racional}

Con relación a esta situación de interés público, nos fue posible identificar la presencia de, a lo menos, dos máximos éticos. Ello se hizo examinando los argumentos proporcionados por los distintos actores presentes en el conflicto, primero, en las fuentes secundarias que fueron consultadas y, luego, en las entrevistas efectuadas a un representante del gremio de la salud, un profesional de la organización no gubernamental vinculada al ámbito de la Educación Popular en Salud (EPES) y, finalmente, al encargado de los temas sociales de la Fundación Libertad y Desarrollo, institución que realiza una reflexión sistemática sobre la realidad social y los desafíos que se plantean a la sociedad y al Estado en este campo.

Estos máximos éticos pueden ser resumidos como sigue: quienes sostienen que la salud constituiría un derecho -el caso de los representantes de los gremios y de los profesionales del mundo de la ONG's- vale decir, un atributo inherente e inalienable a la condición de ciudadano, propuesta que vinculamos con el modelo del Estado Benefactor, y aquellos que estiman que no corresponde hablar de "Derecho a la Salud", pues la Salud, en este paradigma, no constituiría un Derecho, sino una característica que estaría, por una parte, distribuida en función de rasgos como la constitución genética, la edad, el lugar geográfico de residencia, entre otros, y, por otra, que su satisfacción universal e integral no podría constituir hoy una aspiración plausible, pues ningún Estado, por más desarrollo democrático que haya alcanzado la sociedad que administra, tiene recursos económicos suficientes para hacer frente a una demanda de esa magnitud.

La cuestión que estaría en juego para este último sería, entonces, el acceso a la salud determinado esencialmente por la posibilidad de elección, lo que indica que aquello que deberá ser garantizado son las oportunidades de recibir atención en salud y es, en este aspecto, que la sociedad y el Estado han de invertir racionalidad y recursos. En primer lugar, describiremos la argumentación que subyace a la posición de quienes entienden la salud como un derecho. Luego, desarrollaremos el máximo que se centra en la cuestión del acceso a la salud, para terminar caracterizando la posición que el Estado chileno adoptó frente a este conflicto en miras a la constitución de una ética cívica en este campo.

\section{La salud como derecho universal}

Quienes suscriben esta definición entienden la Salud como un Derecho Humano, es decir, una condición universal -lo que en la óptica de la ética comunicativa refiere a la consideración de todo individuo como hablante competente- serían 
absolutos, pues, si entran en conflicto con otros derechos, pasan a convertirse en exigencias a ser satisfechas en forma prioritaria, innegociables, pues la intención de satisfacerlos es condición de racionalidad de la argumentación que entrara a cuestionarlos, inalienables, ya que no pueden ser enajenados sin contradecir la racionalidad misma desplegada en la argumentación (Morales, P. op cit: 2004). Finalmente, se plantea la necesidad de que sean positivizados, aunque ello no constituye condición para ser ejercidos y exigidos, puesto que, al ser condiciones de racionalidad del lenguaje, pasan a ser parte de sus propiedades inherentes, transformándose en exigencias racionales de las cuales son portadoras todas las comunidades humanas (Ibid).

- "La Salud es un derecho humano fundamental, un eje transversal de todas las condiciones de vida del ser humano”20 (Pág. 3).

- La misión de EPES es formar organizaciones en salud con una amplia participación y que todos tengan derecho a la salud y a una vida digna”.

- "Paulatinamente, cuando las mujeres van discutiendo y reflexionando sobre los problemas de salud, se van dando cuenta de que, en realidad, no es castigo divino, no es que porque son pobres no tienen derechos, cuando vamos discutiendo sobre el derecho de salud, que ellas son personas que, por haber nacido, tienen derecho a tener salud, atención y otros derechos.”

Realizamos esta lectura en función de aquello que aparece como el núcleo ético central de este discurso, a saber, la Salud como Derecho Humano fundamental. A él se supeditan las críticas formuladas al actual modelo de salud, particularmente el Plan Auge, los “deber ser” en materia de Derecho a la Salud y el papel central que debiese jugar el Estado en su satisfacción.

20 Representante de EPES.
- $\quad$ "El Auge solamente tiene que ver con la prestación, que es como la llave para el modelo; para solucionar algunos problemas puntuales...” (Pág. 3) “con la Reforma hay una política mal planteada porque el Estado sigue desatendiéndose de su labor, él debe proteger a la población en el tema de la salud...” (pág. $6)$.

Esta perspectiva se remonta a la emergencia del Estado de Bienestar, las Políticas Sociales asociadas a éste y las instituciones de seguridad social, componentes esenciales de un tipo de Estado a través del cual el capitalismo del siglo XIX construye la cuestión social y actúa sobre las contradicciones que le son inherentes (Abrantes, Raquel) ${ }^{21}$. En una óptica similar, Robert Castel sostiene que el Estado de Bienestar "es el resultado de un largo y atormentado período de modernización de la realidad europea, que tiene su apogeo en el viejo continente y en los Estados Unidos durante los treinta años que siguen al final de la segunda de guerra mundial” (...) "Desde aquel momento en adelante hemos asistido a una radical metamorfosis del capitalismo industrial que toma el nombre de mundialización” (...) “uno de los primeros efectos de la mundialización es la pérdida de soberanía de los Estados nacionales. De aquí emerge la dificultad, si no la imposibilidad por parte de los Estados-nación para establecer políticas sociales y económicas que gobiernen el desarrollo económico". Sumado a ello el hecho de que este mismo Estado ya no logra constituirse en límite eco social al crecimiento económico, siendo este aspecto en donde el autor visualiza un quiebre significativo con el pasado (Vecchio, Benedetto, Entrevista a Robert Castel, 2005).

Coincidente con este punto de vista, Montagut señala que las políticas sociales a las que dio origen el Estado de Bienestar poseen un alto con-

21 Las políticas de extensión de la protección social en salud (PSS) como sustento de la formulación normativa Raquel Abrantes Pêgo, Centro Interamericano de Estudios de Seguridad Social, (CIESS) http://www.paho.org/Spanish/DPM/SHD/HP/hp-xi-taller04-pres-abrantes.pdf.

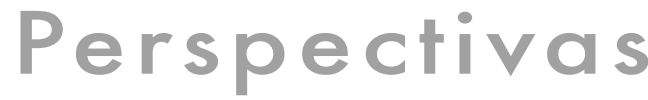


tenido de “objetivos morales”, manifestados en la consideración de igualdad entre los hombres, los derechos humanos o de ciudadanía, que provocan una acción de gobierno en el intento de conseguir la deseada igualdad (Montagut, Teresa: 2000: 21). Afirma que es (...) "a partir del Estado Benefactor del siglo XX” (...) que "el concepto de ciudadanía se extendió hasta la esfera de lo social y económico, reconociendo condiciones mínimas de educación, salud bienestar económico y seguridad como aspectos fundamentales para el ejercicio pleno de los derechos de los individuos” (Montagut, Teresa, op cit: 2000: 22).

- $\quad$ "El Auge solamente tiene que ver con la prestación, que es como la llave para el modelo; para solucionar algunos problemas puntuales...” (Pág. 3) “con la Reforma hay una política mal planteada porque el Estado sigue desatendiéndose de su labor, él debe proteger a la población en el tema de la salud...” (pág. 6)

Dicha concepción, correspondería, en la clasificación que hace Montagut, a uno de los modelos dominantes en materia de Estado de Bienestar: el conservador. Junto a éste, se encontrarían el modelo liberal de carácter residual y el social demócrata, caracterizado por su sello universal e integral y que dan mejor cuenta de las transformaciones experimentadas en el actual escenario de la intervención socio política (Titmuss, Richard en Montagut, Teresa, op. cit: 2000: 10).

- "No debieran existir las Isapres²2, la privatización, estamos definitivamente en contra de la privatización de la salud, de la falta de regulación que existe hoy día, o sea, porque realmente la salud está en el mercado.”

Para Lechner, esta concepción tradicional alude a una idea de totalidad social que hoy día es muy

22 Instituciones de Salud Provisional creadas a partir de las reformas a la salud de la década del ochenta. difícil de sostener por la división de la sociedad en "sistemas funcionales" relativamente autónomos y auto referidos, así como por la presencia de sistemas transnacionales que escapan a cualquier “centro” (Lechner, op. cit 2000).

- "O sea, por el nivel de salario que tenemos los chilenos, es imposible que nosotros podamos financiar la salud al nivel que ellos la quieren poner.. (Pág. 7). Entonces, yo entiendo el reclamo que ellos plantean de la de la clase media, ..porque pretenden traspasar una responsabilidad que no le corresponde a uno, que debemos ser solidarios....(Pág 7)

Sin embargo, estaríamos, para el autor citado, lejos de la disolución del Estado, dado que la multiplicación de actores y la diversificación de estructuras aumentan las demandas de integración social (Lechner, op. cit. 2000). En síntesis, es posible advertir en los argumentos proporcionados por los representantes de ONG's y gremios de la salud, la presencia de un modelo de referencia que identificamos con la Universalidad como característica de la política social. Recordemos que, a partir del año 73', se producen en Chile un conjunto de transformaciones en el modelo de desarrollo que reciben el nombre de "Reformas Neoliberales" y que implicaron, consecuentemente, modificaciones al rol del Estado y a la manera de entender la Política Social al interior del mismo. Entre estos rasgos, se encuentra la subordinación de la política a un modelo de desarrollo centrado en el crecimiento económico, su focalización hacia la pobreza y su implementación dentro de una concepción subsidiaria del Estado que privilegia al Mercado como principal mecanismo de asignación de recursos.

Ello supuso importantes modificaciones en la formulación e implementación de la política social, la que se redujo en el periodo del Estado mínimo, década del ochenta, al otorgamiento de subsidios focalizados a los grupos definidos en situación de extrema vulnerabilidad (Lechner: 2000). Si bien los cambios operados a nivel del escenario político 
chileno y latinoamericano ${ }^{23}$, nos situarían según Sottoli frente a la posibilidad de un paradigma “emergente” que apelaría, además del tema de la focalización, al desarrollo y fortalecimiento del capital social de los "usuarios" junto con la generación de condiciones para el empoderamiento ciudadano, pensamos que el acento economicista del modelo impide que, en la práctica, la Política Social recobre el carácter redistributivo que la caracterizó en el período del Estado Social.

Tanto la información que emergió como producto de la reconstrucción sumaria de los casos como las entrevistas realizadas a los informantes clave, evidencian bajos niveles de incorporación de los límites que el actual modelo impone al rol social del Estado, y por tanto, a su capacidad de producir igualdad, así como también es posible advertir una representación del Estado vinculada a una concepción benefactora del mismo que tuvo lugar, como ya se indicó, con distintos niveles de desarrollo y profundización en el periodo de la Razón Social (Bajoit, 1999).

- “...el círculo de las personas que ya tiene trabajo vamos a ser los que vamos a financiar a esos pobres de los cuales el Estado no se responsabiliza y más encima los posterga... Lagos tiene una política mal planteada, no es una política para solucionar los problemas de los pobres sino que traspasa la responsabilidad de la pobreza a quienes tenemos trabajo y a nosotros nos sigue exprimiendo con los impuestos...” (Pág. 6)

La crisis en la salud pública de nuestro país se expresaría, según Juan Luis Castro, dirigente del Colegio Médico de Chile, en la existencia de serios

23 Entre los cuales se destacan, el advenimiento democrático en todo el continente, el reconocimiento de los Estados de la importancia de incorporar la idea del fortalecimiento del capital social y del empoderamiento ciudadano como ejes de la política social y la ampliación del concepto de focalización, circunscrito inicialmente al ámbito de la pobreza, para transitar hacia la noción de exclusión social en un sentido amplio. problemas en la atención tales como las largas horas de espera, las hospitalizaciones en pasillo o la falta de información, entre otras. Y agrega que "No puede haber derecho a la atención garantizado por el Estado cuando hoy el principal establecimiento de urgencia no tiene ni una cama disponible al mediodía del primer día de la semana. Esto es lo que hemos denunciado y lo que le estamos advirtiendo a la gente para que sepa cuáles son los derechos que pueden exigir de verdad frente a esta situación catastrófica".

Como plantea Manuel Antonio Garretón, se trata de Matrices Socio Políticas que equivalen a formas particulares de concebir el sentido, rol y funciones asociadas a cada actor del desarrollo. Ello hace que, frente a un cierto tipo de Estado, correspondan, también, tipos de relación entre actores, en este caso, entre Estado y Sociedad Civil. Esta concepción de Estado centrada en su misión de proteger y garantizar el Bien Común, sería propia de la Matriz Nacional Popular, la cual se caracterizó por una relación entre la base social y el Estado mediada por partidos políticos y organizaciones sociales y laborales, como sindicatos y otros. Fueron estas instancias las encargadas de vehicular las demandas sociales en materia de satisfacción de necesidades o reivindicaciones sociales y políticas.

Esta matriz tendría, entonces, como componente esencial, el trabajo, en un periodo de fuerte desarrollo industrial, y la vida colectiva desplegada en torno a la articulación, más o menos conflictiva según periodo histórico y correlación de fuerzas, entre este conjunto de actores (Garretón).

- “...hay una crisis de debilidad en los partidos políticos que puedan generar propuestas, hoy día nadie cree en las organizaciones formales de la sociedad... nadie cree en la política... y el Estado no responde, no es protector; entonces la gente no ve una solución en los partidos políticos ni en las organizaciones formales.” (pág. 11).

- $\quad$ "El 5 de Noviembre de 2002, los diputados Perspectivas 
Patricio Cornejo (DC) y Enrique Accorsi del Partido por la Democracia (PPD), ambos médicos, habían declarado a la prensa que postergarían las votaciones de los proyectos relacionados con el Plan Auge debido a “amplias diferencias" en el bloque oficialista y a la escasa representación de las posturas de los gremios en lo que iba transcurrido del debate".

- "Hoy se escucha a parlamentarios de la Concertación criticando duramente estas situaciones, pero no son más que discursos electoralistas, pues fueron ellos quienes, junto a la derecha, votaron favorablemente la Reforma presentada por el Gobierno, con la férrea oposición de los Gremios de la Salud, dejando de manifiesto que los honorables sorprendentemente, no solo no escuchan a la ciudadanía ni a los trabajadores, sino que aprueban leyes cuyos contenidos desconocen por presiones políticas" (Consejo Directivo Nacional, CONFENATS, 19 de junio de 2004).

- El País ha podido constatar, en estos días, el nivel de confusión y avance que experimenta la llamada "Reforma Sanitaria Neoliberal", respecto a los derechos y prerrogativas de los pacientes y trabajadores del sector, así como la falta de financiamiento del AUGE, y su implementación difusa y contradictoria (Ibid).

Castel refuerza este punto de vista al sostener que: "La inestabilidad y la desocupación de masa son, en efecto, los elementos constitutivos del capitalismo surgido de la crisis de los años setenta. No hay duda sobre el hecho de que estamos frente a la superación de una organización productiva basada en trabajo repetitivo y normalizado. En el pasado, frecuentemente se ha hablado de organización científica del trabajo, de taylorismo: expresiones que connotaban de todos modos una dimensión colectiva de la relación de trabajo. Ahora, en cambio, asistimos a la propagación de una individualización de la relación de trabajo. Los trabajadores tienen que ser móvi- les, flexibles, emprendedores, polivalentes pero precarios, y con un sistema de protección social reducido a su mínima expresión. Si el capitalismo quiere sobrevivir a sí mismo, seguramente tiene que repensar los sistemas de protección social, pero, de algún modo, tiene que garantizarlos” (Castel en Vacchio, op cit, 2005).

El desafío para los partidarios de la Salud como Derecho Universal, sería, en consecuencia, pensar los sistemas de protección a la luz de los nuevos escenarios socio políticos, sin abandonar la lucha por el aseguramiento y exigibilidad de los derechos en este campo, no sólo en materia de Salud, sino también, de trabajo, particularmente para los funcionarios del sistema. No obstante, el peso de las transformaciones operadas fundamentalmente en el mundo del Trabajo y la previsión social asociada a un sistema laboral como el descrito por Castel -generadores de altos índices de precariedad laboral-hacen más urgente la necesidad de garantizar protección, siendo, paradójicamente, también el resultado de políticas que favorecen la expansión del capital por sobre las condiciones laborales de los trabajadores, políticas que se expresan, entre otros fenómenos, en las restricciones al gasto público, como efecto del ajuste estructural exigido por los organismos financieros internacionales y por la debilidad del Estado chileno, en este caso, de aumentar los recursos orientados al gasto social vía impuestos. Así como también, la lentitud de las propuestas legislativas destinadas a modificar los actuales sistemas de administración y financiamiento en materia de salud y seguridad social.

Sobre este punto, Abrantes llama la atención que la misma crítica hecha al Estado Benefactor empezó a hacerse también a las reformas neo liberales. Estas comenzaron a ser calificadas de ineficientes en su propósito de contrarrestar los efectos del ajuste. Aun habiendo sido formuladas a sabiendas de los impactos negativos que dichas medidas tendrían sobre el aumento de la pobreza, medidas que tampoco fueron capaces de mejorar las prestaciones de la seguridad social. La ilusión de fortalecer el desarrollo económico y el uso del excedente resultante de este 
proceso para la resolución de problemas sociales se vio también truncada. "Se inició, entonces, todo un período de críticas a las reformas en el sentido de que el nuevo modelo de desarrollo, que surge de las políticas de ajuste estructural, tiene como una de las características predominantes la de no incorporar una red de protección social capaz de reemplazar a la que anteriormente proveía el Estado" (Abrantes, Raquel, op. cit; 2002: 3).

Los Estados Nacionales y los partidos políticos están llamados a jugar un papel importante en la promoción de proyectos de desarrollo endógeno que contrarresten el peso de los sistemas globalizados. Ello requiere indudablemente la colaboración de otros sectores tales como la sociedad civil organizada y un empresariado social y ambientalmente responsable. Esto supone modificar el contenido y el tipo de relaciones sostenidas hasta hoy entre los distintos componentes o agentes del funcionamiento social. Sin embargo, indica Alguacil Gómez, "el proceso de construcción de ciudadanía vinculado a la consolidación del Estado de derecho se ha fundamentado en un modelo político de democracia representativa incapaz de incorporar plenamente a los ciudadanos en los asuntos públicos, conformando, por tanto, una ciudadanía pasiva. El Estado del Bienestar no ha sido capaz de superar un paradigma paternalista donde las necesidades son definidas por el Estado y donde los derechos asistenciales, los servicios y prestaciones, han terminado siendo, por su significado y por su motivación a la pasividad, un impedimento para consolidar una ciudadanía social y activa, una participación real en las decisiones y en la construcción de los objetivos colectivos. La no implicación plena de los ciudadanos en la política y en los asuntos colectivos hace de la propia política una dimensión muy vulnerable frente a los procesos económicos y territoriales. Precisamente, el cambio de ritmo que implica la globalización (la mundialización de la economía) y la ofensiva neoliberal, que se fundamenta en la proclamación de una mayor autonomía de la economía respecto de la política, implica un estancamiento, cuando no un retroceso, de los derechos de ciudadanía que provoca la necesidad de replantearse los procesos que llevan a la misma” (Alguacil, Gómez: 2002).

Así, observamos que la demanda por participación democrática directa se hace patente tanto en conflictos ambientales como el observado en torno al Relleno Sanitario Santa Marta, como en relación a la Reforma de la Salud, lo que se aprecia en los testimonios recopilados en el análisis de prensa y en el discurso de los entrevistados. Tras la reflexión llevada a cabo por la Social Democracia europea como continuadora de la tradición redistributiva iniciada por el Estado Benefactor entre las décadas del 20' al 70', se observa la importancia de la generación de un diálogo social heterogéneo y amplio, que posibilite la formulación de normas de corresponsabilidad que establezcan no sólo normativamente sino también, en términos fácticos, los alcances, limitaciones y posibilidades de la acción de cada uno de estos actores. Ello, puesto que es a partir de su explicitación que se hace posible repensar la continuidad de los principios y valores que sostuvieron al Estado Benefactor, atendiendo al actual contexto.

Lo anterior no significa, en modo alguno, evacuar el tema del conflicto, sino más bien considerarlo como un componente inherente al ejercicio democrático, haciendo la distinción entre lo que Borja denomina un conflicto simétrico de uno asimétrico. En el primero, las partes tienen posibilidades de negociar en igualdad de condiciones pues manejan similares niveles de información respecto de las causas y consecuencias del problema que genera el desacuerdo y, al mismo tiempo, tienen oportunidad de intervenir para modificar el curso de los acontecimientos en un sentido que favorezca sus propios intereses. En el segundo, en cambio, hay uno o más sectores que sólo "padecen” las consecuencias de decisiones que han sido tomadas por otros y respecto de las cuales no han tenido ninguna posibilidad de participación (Borja: 2003).

Asimismo, los argumentos del gremio de la salud

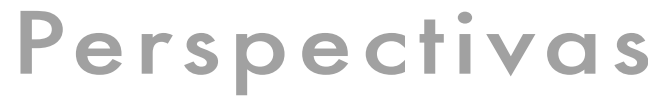


resultan una combinación entre defensa de intereses corporativos y preocupación por la justicia social que no se resuelve apropiadamente; no quedan claros los mecanismos a través de los cuales podría materializarse esta aspiración, especialmente cuando los ideales de justicia entran en conflicto con los intereses de los gremios -en particular, el gremio médico- como se deduce de la opinión formulada por sus dirigentes respecto de algunas medidas consideradas por el Plan Auge y que afectaría las prerrogativas de las que gozan en su doble condición de funcionarios de la salud pública y prestadores privados de un sistema escasamente regulado.

Tampoco es posible establecer, a través de sus dichos, lo que estarían dispuestos a "perder" como resultado de las concesiones que necesariamente deberán hacer los actores que buscan construir acuerdos cooperativos que garanticen la equidad del conjunto.

- “...Con eso hubo logros importantes desde el punto de vista de la contribución que tuvo esta organización (La Confenats) en la participación; pagaron horas extraordinarias, la gente tenía más beneficios....” (Pág. 1)

- “..el círculo de las personas que ya tiene trabajo vamos a ser los que vamos a financiar a esos pobres de los que el Estado no se responsabiliza y más encima posterga... Lagos tiene una política mal planteada, no es un política para solucionar los problemas de los pobres sino que traspasa la responsabilidad de la pobreza a quienes tenemos trabajo y a nosotros nos sigue exprimiendo con los impuestos..." (Pág. 6)

En síntesis, tenemos la impresión de que la sustitución en el discurso del gobierno de la Concertación del concepto de justicia por el de equidad, no ha estado acompañada de una reflexión acerca de su real alcance y sentido, apareciendo vinculada a la idea de solidaridad, que, tal como indica Cortina, no se puede imponer. Una sociedad democrática no está obligada a ser solidaria, pero tiene el deber de ser justa. Si tomamos la idea de justicia como equidad a la manera Rawlsiana - en cuanto a garantizar el acceso a un sistema de derechos y libertades individuales compatible con un sistema de derechos y libertades para todos y la protección de los individuos menos aventajados - debemos debatir respecto de la manera de conciliar libertad individual y libertades para todos y generar condiciones para que este debate se dé en el marco de una compromiso político y social con los más vulnerables. Respecto a este punto, remitimos al interesante trabajo de Jorge Iván González publicado en la Revista Espacio abierto $\mathrm{N}^{\circ} 2$, de Septiembre de 2002 titulado "Salud y Seguridad Social: entre la Solidaridad y la equidad", que reflexiona en torno a los alcances y limitaciones de cada una de estas dos nociones a la luz de las recientes reformas que, en estas materias, han sido llevadas a cabo en Colombia.

\section{La salud como derecho a la atención en salud: la teoría de la elección racional}

El segundo máximo que es posible identificar en los discursos articulados en torno a esta situación de interés público, remite a una restricción de la concepción universalista del derecho a la salud. En primer lugar, se pone en cuestión que la salud sea un derecho que el Estado deba garantizar. Se la concibe más bien como un atributo personal cuya posesión el Estado no puede asegurar, siendo su tarea comprometer acciones que garanticen el acceso a la atención en salud, generando condiciones para que todos los chilenos tengan esa opción.

- "Igualdad de oportunidades es acceso a la salud, no derecho a la salud.” (pág. 16).

- “También creemos que cada persona tiene libertad para escoger el sistema de salud que quiera dentro de sus capacidades económicas obviamente” (pág. 1,9). 
Las reformas de la salud han implicado, en el caso chileno, una tendencia cada vez más creciente de participación del sector privado en la gestión y administración de los seguros y prestaciones sociales, abandonando la pretensión universalista sostenida por el máximo antes descrito.

- “Tiene un rol bastante importante (el sector privado) porque, a través del rol subsidiario del Estado, puede sustituirlo en áreas que no se justifica que el Estado participe. Por eso es que son relevantes las concesiones de hospitales públicos porque el Estado tiene una restricción de recursos...el sector privado debe participar en el área del seguro, debe participar en el área del Estado con estándares que van a ser fiscalizados por el Estado; hay una relación simbiótica entre el Estado, el sector privado y los usuarios.” (pág. 5)

- "Para Castro, gran parte de los problemas financieros del sector público se originan en el inadecuado sistema de incentivos bajo el cual funciona. El financiamiento de los prestadores públicos no está orientado a la gestión y los directivos de los establecimientos no son, en la práctica, responsables de su administración, manteniéndose en sus cargos a pesar de mostrar cierta incompetencia” (Castro, Rodrigo: op. cit: 2002).

- $\quad$ "En segundo lugar, los recursos estatales para financiar las instituciones de salud se traspasan teniendo en cuenta elementos históricos como las remuneraciones, infraestructura y equipamientos, sin considerar la adecuada utilización de éstos en la efectiva solución de los problemas de salud de las personas. Asimismo, se utiliza mayoritariamente un sistema de facturación por atención prestada (FAP), destinado a sufragar los gastos en bienes y servicios y los recursos para inversión se asignan desde el nivel central con criterios discrecionales y poco transparentes” (Castro, Rodrigo: op. cit: 2002).
Siguiendo lo planteado por Abrantes respecto de las tendencias introducidas por las orientaciones neoliberales, es posible observar, en esta situación, que la propuesta consiste en "garantizar un piso básico, dándole un carácter más asistencial o compensatorio que puede ser entendido como una salida que no está basada en el reconocimiento de un derecho que avizoraba, dentro del pensamiento de Marshall, generar un estándar de igualdad entre todos" (Abrantes, ibid).

En consecuencia, lo que plantea la salida neoliberal es la separación entre lo público y lo privado postulando, como tarea de lo público, -en el ámbito de la salud-solamente la de cuidar de la población que no entra en la competencia del mercado, o sea, cuidar de los pobres. La propuesta es la de universalidad restringida, basada en la valoración del individuo y de su acción racional, considerando que estos individuos están dispuestos a compartir el riesgo, asegurando los gastos en el futuro, de acuerdo con su capacidad de pago.

- $\quad$ "El Estado va a ser el que va a financiar estos obstáculos, le va a pagar a aquellos FONASA A y B sin discriminación de acceso...” (pág. 11).

- “...hay sectores más vulnerables, más desinformados con los que el Estado tiene que cumplir un rol subsidiario asistencial: a la tercera edad, los menores, etc”.

- “...los usuarios requieren estar más informados. No pueden tener un rol pasivo respecto a su salud... o sea tienen que ser preactivos, las personas tienen que tomar un rol activo no pueden estar pacientes a que el Estado o el sector privado los vaya a buscar..” (pág. 5)

Las declaraciones del representante de Libertad y Desarrollo pueden ser leídas desde la Teoría de Elección Racional, que postula como supuestos: la dependencia de las prácticas sociales de la intención de los sujetos que las realizan, que la acción social es fundamentalmente racional, que requiere

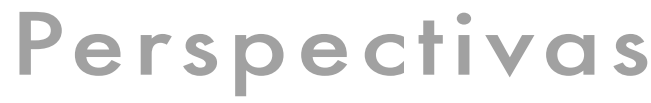


de información lo más completa y verídica posible y de la capacidad de los sujetos de distinguir entre situaciones de riesgo e incertidumbre, asumiendo las consecuencias de sus actos.

- "Igualdad de oportunidades es acceso a la salud, no derecho a la salud.” (pág.16).

- “...también creemos que cada persona tiene libertad para escoger el sistema de salud que quiera dentro de sus capacidades económicas obviamente” (pág.19).

- “Tiene un rol bastante importante porque a través del rol subsidiario del Estado puede sustituirlo en áreas que no se justifica que el Estado participe. Por eso, es que son tan importante las concesiones de hospitales públicos porque el Estado tiene una restricción de recursos.. el sector privado debe participar en el área del seguro, debe participar en el área del Estado con estándares que van a ser fiscalizados por el Estado, hay una relación simbiótica entre el Estado, el sector privado y los usuarios." "esas nuevas tecnologías se desarrollan para el $1 \%$ más rico de la población mundial que está dispuesto a pagar, pero no se piensa en el 99\% restante que está bajo o dentro del ingreso (mínimo), para ellos hay un estándar desde el punto de vista de la salud..” (pág. 3)

- “El Estado tiene que dar las directrices, tiene un rol rector, normativo a través de su brazo que es el Ministerio de Salud.. tiene que ser también un fiscalizador respecto a la calidad y por eso que existe una Super Intendencia de Salud...” (pág. 5)

- “...es un problema más bien de diseño original, a pesar de que el diagnóstico me parece correcto que hay que priorizar los recursos, es decir, priorización financiera y sanitaria... pero en salud es redifícil, o sea, todos quieren que no sean 56 enfermedades quiero que sean 100 mil, todas con cobertura a nivel de Suecia” (pág. 7).
La reforma de salud y el establecimiento del aseguramiento individualizado supone la existencia de consumidores que actúan racionalmente, capaces, por sus conocimientos, de tomar decisiones racionales, consideradas las mejores para sí mismos. En esta perspectiva, el Estado no solo debiera garantizar condiciones para acceder a la atención libre en salud, sino que debe también proveer mecanismos de información, difusión y educación para prevenir problemas y promover la salud. No obstante, nos encontramos aquí con limitaciones culturales importantes que dicen relación con la forma en que prestadores y usuarios se aproximan al derecho a la salud, el tipo de acciones que es necesario ejecutar y el rol que cabe a cada uno de estos actores.

- $\quad$ No hay cultura desde el punto de vista de la demanda, ni tampoco desde el punto de vista de la oferta de los prestadores, ni de los usuarios del sistema por prevenir, por promocionar en salud, se hace muy poco a nivel de colegio, a nivel de redes de salud primaria; a nivel de consultorio por entregar información para prevenir.” (pág. 3).

La ausencia de cultura desde el punto de vista de la demanda en salud y la falta de una actitud preventiva y de auto cuidado en la población estaría redundando negativamente en el sistema público, el que se vería sobre exigido y sobre demandado en razón de la ausencia de estos componentes. Esta perspectiva constituiría, para Castel, una concepción de la protección social que niega el carácter universal e incondicional de los derechos sociales y que el autor identifica como el «workfare», es decir, un conjunto de políticas sociales en base a las cuales se tiene derecho a algunos servicios sólo si se trabaja. En épocas de desocupación masiva y de inestabilidad difusa, ello significaría, para este autor, una negación del carácter universal de los derechos sociales y, por lo tanto, un non sens [sin sentido], “(...) pues supone que se puede garantizar un conjunto de servicios sociales mínimos sólo si quien lo necesita demuestra que puede prescindir de ellos, trabajando o poniendo en pie una pequeña 
empresa” (Castel en Vaccio, op cit). Para Castel, la contradicción de este capitalismo es pedir autonomía, polivalencia e iniciativa y ofrecer inestabilidad y ausencia de protección social (Ibid).

\section{Reflexiones finales}

Una de las primeras cuestiones que nos llama la atención a partir de este estudio es la homogeneidad de máximos que nos fue posible reconocer en el conflicto del Relleno Sanitario. Todos los que, desde la sociedad civil, se opusieron a su instalación comparten un ideal que sostiene la subordinación de los intereses del capital a la protección del medio ambiente, los recursos naturales y la calidad de vida de la población. Curiosa convergencia teniendo en cuenta que, de acuerdo a lo señalado por Cortina, los derechos medio ambientales serían constitutivos de la Tercera Generación y aquellos en relación a los cuales existe más baja conciencia ciudadana y menos reconocimiento legislativo.

No obstante, este tipo de conflicto pareciera concitar más adhesión que los desacuerdos generados en torno a temas tales como el Derecho a la Salud o los límites y/o prerrogativas a la libertad de conciencia. Sería interesante profundizar en las razones que subyacen a este consenso: ¿Quizás su transversalidad? ¿Quizás el hecho que su deterioro compromete efectivamente la vida y los recursos del planeta y, por ende, del conjunto de sus habitantes sin distinciones de ningún tipo? ¿O tal vez se trate de una clase de conflicto históricamente muy reciente cuya reivindicación no se asocia a ningún grupo o segmento particular, respondiendo mejor al perfil heterogéneo que activa, en la actualidad, la acción ciudadana? Creemos que se trata de un aspecto interesante de seguir explorando.

Respecto a la situación de interés público suscitada en torno a la reforma de la salud, cabe señalar que existiría, en la ciudadanía beneficiaria del sistema público, una expectativa acerca del rol y funciones que le competen al Estado, similar a la sostenida por quienes defienden la salud como Derecho. Ello genera una distancia entre las expectativas de ambos actores, distancia que se acentúa en la medida que la población beneficiaria de estas reformas, desconoce su real sentido, alcances, limitaciones, posibilidades y modalidades operativas de funcionamiento.

Así como otras reformas que han sido impulsadas durante el gobierno del Presidente Ricardo Lagos, éstas no se han visto acompañadas del trabajo educativo -masivo y sistemático- que hubiese supuesto la apuesta por un cambio de actitud. Cambio de actitud orientado, en primera instancia, a promover la generación de condiciones favorables a la adhesión ciudadana (información, identificación, cohesión, pertenencia) en tanto no es suficiente, en el marco de la ética cívica, que una sociedad reconozca ciertos Derechos y Valores como legítimos, sino que también esté dispuesta a resguardarlos y defenderlos.

Pareciera que esta adhesión se pone en juego esencialmente en situación eleccionaria, haciéndose pertinente la crítica formulada por Cortina y otros, a un estilo de Estado que debiera, en un contexto de derechos complejos, fortalecer el capital social y cultural de los ciudadanos en lugar de manipularlos visualizándolos esencialmente como potenciales electores.

Sostenemos, en consecuencia, que el Estado chileno no estaría jugando un papel relevante en la creación de condiciones favorables al establecimiento de acuerdos normativos que pudiesen perfilar la formulación de una ética cívica en lo que se refiere a los casos estudiados. Ello podría hacerse extensivo a otras situaciones, las que debieran ser profundizadas y contrastadas con los hallazgos del presente estudio.

Lejos estamos, entonces, de una sociedad donde se respete, se aliente y se resguarde el tercer componente de la ética cívica, a saber, la actitud dialógica. Ello, pues su puesta en práctica en pos de la construcción de acuerdos cooperativos en este marco supone que, como resultado de estos

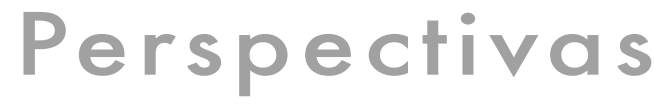


acuerdos, los hablantes produzcan normas de convivencia social en igualdad de condiciones de información y de poder-el que de existir-quedaría momentáneamente suspendido a favor de la simetría que debiera siempre caracterizar el setting de la interacción comunicativa.

Tanto en el caso de Santa Marta como de la Ley de Divorcio y la Reforma de la Salud, la actitud del Estado chileno se ha caracterizado por la ausencia de diálogo social y de debate público en torno al sentido, importancia y necesidad de adhesión y participación ciudadana en los cambios que cada una de estas medidas ha supuesto. Ello resulta contradictorio con los principios que sostienen las "elecciones individuales" al interior de la Teoría de la Elección Racional -que estaría a la base de la Política Social en el contexto de un modelo centrado en el crecimiento económico- donde se suscribe la relevancia que los consumidores actúen racionalmente y que sean capaces, por sus conocimientos, de tomar decisiones racionales, consideradas las mejores para sí mismos.

Por una parte, una población que desconoce y no comprende -como fue señalado por la mayoría de los entrevistados que cuestionan la legitimidad del Auge- el alcance de los cambios propuestos por una Reforma -cualquiera sea su naturaleza- limita sus posibilidades de "elección racional" en la medida que desconoce qué elegir y cómo ordenar "racionalmente" su elección. Por otra parte, si esas condiciones de información y empoderamiento ciudadano se dieran en la realidad, nada más que la teoría podría augurar la orientación que adquirirán, en la práctica, las conductas de los ciudadanos, en este caso, los usuarios del sistema público. A menos que estemos en presencia de una teoría de pretensiones deterministas o predictivas, lo que en el contexto del debate epistemológico actual resulta, por decir lo menos, contestable.

En una perspectiva ético política como la suscrita por este equipo de investigación, la democracia y sus posibilidades de construcción y fortalecimiento supondrían, antes que nada, generar condiciones de participación y diálogo deliberativo y abierto, cuyo curso se vuelve, en parte, imprevisible, pues obedecerá a la capacidad de acción o historicidad de cada actor sobre sí mismo y sobre los demás y en las garantías que el sistema político otorgue para producir esta negociación en condiciones de equidad (Touraine: 1997).

Reguillo analiza este punto en términos de una tensión constitutiva de lo social, cual es la necesidad de un Estado rector lo suficientemente fuerte para regular y arbitrar el conflicto social y, al mismo tiempo, la posibilidad de generar instrumentos y procesos organizativos que acoten el poder del Estado. En este concepto, la ciudadanía sería entonces una categoría clave que se levantaría precisamente como una mediación que, por un lado, define a los sujetos frente al Estado nación y por el otro, protege a los sujetos frente a los poderes del Estado (Reguillo, Rossana: 2003).

Quisiéramos subrayar que el eje de nuestra argumentación no está en insistir en la obligatoriedad del Estado, al menos en el campo de la Salud, de asumir la tarea de brindar integralidad y universalidad, sino más bien en preguntarnos qué puede y debe ser exigido desde la sociedad civil y desde una ciudadanía activa, en términos de condiciones de posibilidad de la democracia y del ejercicio de Derechos Ciudadanos. Ello, asumiendo que hay demandas que no pueden ser satisfechas en la actual concepción que el Estado tiene de sí mismo y del rol al que lo limita el modelo que ha escogido para promover el "desarrollo”. Quizás la tarea de la Sociedad Civil sea, precisamente, debatir en torno a la legitimidad del modelo y a la capacidad e interés que éste tiene, por satisfacer demandas sociales. Para Castel, la generación de un pacto social se constituye en una condición de posibilidad del propio capitalismo: "Si el capitalismo quiere sobrevivir a sí mismo, es necesario un pacto político reformista que garantice protección y derecho social universal. En la defensa del Estado de bienestar no hay nada de revolucionario. A lo sumo, buen reformismo" (Castel en Vacio, op cit.). 
En el planteamiento Habermasiano, las normas ideales y universalmente válidas serían de corresponsabilidad de quienes toman parte en el discurso, la igualdad de derechos y la susceptibilidad de consenso de todas las soluciones a los problemas que presenta la existencia social (Morales, Paulina: 2003). Es por ello que se torna fundamental generar un diálogo entre quienes serán afectados positiva o negativamente por las normas producidas y pactadas, lo que no ocurre en ninguna de las situaciones descritas en las cuales los hablantes se perciben a sí mismos como meros receptores de las decisiones de otros. De ahí que la noción de responsabilidad social empresarial -aunque objeto de críticas y suspicacias por quienes ven en ello una paradoja- y el hecho de insistir en que los empresarios constituyen efectivamente parte de la sociedad civil, sea esencial al debate acerca de la constitución de una ética cívica.

Respecto a esta polémica, crear condiciones que posibiliten los discursos es fundamental, sobre todo, como señala Morales, si ello -como en el caso de las situaciones reseñadas- "se visualiza al amparo de una diferenciación categorial entre la infraestructura normativa de una sociedad y su forma práctica de vida, ambas expresadas en un entramado de prácticas culturales, convenciones, modelos de identidad, instituciones, determinados y/o concretados en cierto momento histórico" (Morales, 2003).

Esta constatación supondría, en los casos que nos ocupan, dos cosas. Una, el grado en el cual la institucionalidad que establece los límites normativos a cada situación posibilita o no la generación del diálogo y los acuerdos referidos, y, por otra, si lo sostenido por los distintos actores involucrados en las situaciones deja en evidencia distancias o proximidades entre el núcleo normativo al cual adhieren colectivamente al menos en el discurso, y las prácticas sociales concretas asociadas a su acción; lo que daría cuenta de mayores o menores niveles de correspondencia con las normas declaradas.
No obstante, continúa Morales citando a Honnet, a los particulares modos de vida de una sociedad le es siempre inherente una infraestructura normativa que fija las condiciones de justicia social bajo las cuales surgen y se reproducen las convenciones culturales y las instituciones sociales que, en el caso de la presente investigación, correspondería a los mínimos (Morales, Paulina. Op. cit 2003). Aquí, la ética del discurso debe distinguir también normativamente los condicionamientos socio estructurales para su propia aplicación, en el sentido de que sólo puede valer como justa aquella sociedad que, en su infraestructura normativa, dispone los presupuestos para diálogos libres de dominio que garanticen a todos sus miembros la oportunidad de una participación igualitaria y sin coerción en aquellos (Morales, P, op. Cit. 2003).

Un desafío para Trabajo Social, desde el punto de vista investigativo, sería, por ejemplo, profundizar en el grado de democratización alcanzado por la infraestructura normativa de las instituciones que en nuestro país organizan la vida social, a saber: la familia, el sistema educativo (escuela, establecimientos de educación superior) el mundo del trabajo, de las organizaciones de la sociedad civil, de la relación entre organizaciones económicas, por mencionar algunas. No obstante, conviene sobre este punto recordar que estas condiciones son de carácter ideal puesto que, en la ética comunicativa, el consenso que legitima las normas no puede ser sólo fáctico, sino también contra fácticamente anticipado como expresa Cortina, ya que el diálogo no suele reunir las condiciones de simetría adecuadas, ni se garantiza suficientemente la atención a los intereses de los afectados (tanto presentes como ausentes).

Con relación a la cuestión de entender los Derechos Humanos, en términos de generaciones, quisiéramos señalar que, si bien esta propuesta goza de aceptación al interior de importantes círculos intelectuales y políticos, es posible y también deseable presentar algunas tensiones contenidas en ella y a la viabilidad de producir acuerdos bajo la égida de 
la ética del discurso. Una perspectiva crítica a la consideración de los Derechos Humanos en términos de "generaciones" es la que sostiene P. Meyer Bisch. Dicho autor, apoyándose en los trabajos de Korel Vasak, sostiene que los Derechos Humanos no han sido todavía asumidos como un sistema unitario y no jerarquizado donde cada uno de los Derechos invocados vale por sí sólo más allá de la generación a la pertenezca o el nivel de fundamentación ético y teórico/ metodológico que posea y, al mismo tiempo, forma parte de un todo. Ello lo lleva a plantear la indivisibilidad de los derechos del hombre y su necesaria interdependencia.

Meyer Bisch, fundamenta su tesis señalando que falta trabajo y comprensión interdisciplinaria entre los distintos Derechos que constituyen la Declaración. El hecho de que haya habido hasta ahora una comprensión restringida de sus oportunidades de materialización, asociando los Derechos Sociales, por ejemplo, al Estado y sus posibilidades materiales y políticas de concretarlos a nivel de la ciudadanía, han inducido a las sociedades a asumirlos como Derechos/Programas, tecnocratizando su sentido y postergando al infinito la urgencia de garantizar su ejercicio sobre todo con relación a grupos vulnerables, como los pobres (Meyer, Bisch, 2000).

Plantear el tema de los Derechos Humanos en términos de generación de derechos suscita, además, una serie de críticas tanto desde el punto de vista histórico como metodológico. Algunos sostienen que tal progresión no es observable en todas las sociedades. Hay derechos sociales que surgieron antes o simultáneamente a los derechos civiles. Se cuestiona, al mismo tiempo, la tendencia que se refleja en la concepción de Generación de Derechos a diferenciar entre derechos de los colectivos o de los individuos. A juicio del autor, todos son derechos del individuo, no obstante algunos de ellos acentúan la dimensión grupal o comunitaria.

Sobre el punto, cabe citar una investigación sobre ciudadanía llevada a cabo por la Facultad de Ciencias Sociales de la Universidad de Chile entre los años 98 y 99. En la investigación referida se concluye que el caso chileno demuestra, por ejemplo, que no todas las sociedades han entrado de la misma manera al debate relativo a los Derechos Ciudadanos. Arrau y Avendaño, sus autores, aventuran la hipótesis según la cual el proceso de ciudadanización "ha tenido una singular configuración si tenemos en cuenta los clásicos aportes de T.H. Marshall (...) tras una revisión histórica que comprende desde fines del siglo XIX hasta los años ochenta del siglo XX, se observa que muchas veces el propio concepto de ciudadanía aparece poco claro. En otras, los derechos sociales y políticos tienen una primacía sobre los derechos civiles. En las últimas décadas, sin embargo, con la lucha por los derechos humanos, los elementos civiles han adquirido particular relevancia”24.

La acentuación en el carácter generacional de los derechos, y, por lo tanto, en la progresión de su aparición, ha redundado, según Meyer Bisch, negativamente en las posibilidades de la sociedad actual de satisfacer las necesidades de las mayorías en una tarea que es, primero que nada, un imperativo social, no sólo del Estado, sino de la sociedad en su conjunto. Se trata de asumir de una nueva manera los derechos humanos, más que como categorías, como subsistemas en interacción, modificar uno de ellos, sostiene el autor, supone retro actuar sobre el conjunto (Meyer Bisch, 2000, 128).

Para Jordi Borja, en tanto, los derechos correspondientes a las denominadas "generaciones de derechos”, que él llama “derechos simples”, serían parte de un sistema que debe ser revisado en pro de su complejización, dando paso a un nuevo modelo que él denomina "Derechos Complejos". Esto significa, por ejemplo, que ya no basta con garantizar el derecho a la educación -que se entendió históricamente como educación primaria y

24 Arrau, A y Avendaño, O: "Notas acerca del desarrollo de la ciudadanía en Chile", Universidad de Chile, Facultad de Ciencias Sociales, documento № 1, Santiago, Chile, 2001: 1 . 
secundaria- sino más bien insistir en el derecho a la educación permanente, exigencia que se condice mayormente con los rasgos del actual escenario. Asimismo, el derecho a la participación política a través del voto, en el contexto de la democracia representativa, no resulta suficiente hoy en día para dotar a la ciudadanía de poder y capacidad de influir en las decisiones que afectan directamente su vida y cotidianidad.

En ese sentido, nuestras sugerencias de intervención irían en la perspectiva de promover y generar dispositivos de diálogo e intercambio social, de conversación y de debate en torno al tema de los valores y los derechos, y ello hacerlo en el contexto de una interacción que tenga en cuenta algunas reglas básicas para la construcción de acuerdos y/o la gestión del conflicto (simetría, inteligibilidad, aceptación de los interlocutores como válidos) asumiendo la tensión entre niveles de desarrollo institucional y necesidad de un consenso contra fácticamente anticipado.

Los programas de formación en Trabajo Social se vuelven instancias privilegiadas para el desarrollo de habilidades sociales y comunicativas en los jóvenes, requeridas para la adopción de este tipo de conductas y actitudes. Destacamos el papel de los Talleres de Formación Socio Profesional I y II y de las prácticas, columna vertebral de la propuesta de formación del Departamento de Trabajo Social de la UCSH, y su intención de potenciar las habilidad de atención y escucha (condiciones mínimas para el establecimiento de acuerdos racionales), capacidad para identificar los propios prejuicios y modelos de construcción de la realidad social implicados en la mirada que tiene el individuo sobre el mundo, y el respeto por sí mismo y por el otro, como eje articulador de la conducta individual y profesional.

Además, el Trabajo Social cuenta con una rica tradición en materia de Intervención y Educación Social que facilitaría la tarea de pensar cómo generar estos dispositivos en la práctica: tradición de trabajo grupal/comunitario, educación popular, investigación, acción participativa, metodologías cualitativas, activas y participativas, todo lo cual puede ser inscrito en el marco de lo que hoy en día conocemos como la “Educación para la Paz”. Ella puede ser entendida "como un proceso dirigido tanto a los individuos como a la sociedad para que actúen, conforme a los principios contenidos en la Declaración Universal de los Derechos Humanos y todo el hábeas jurídico internacional que los desarrolla, a favor del desarrollo sostenido de los pueblos, la protección y conservación del medioambiente, la aspiración y acción en pro del desarme, el fortalecimiento de la convivencia social y la solución no violenta de los conflictos. La educación no consiste en enseñar un nuevo conjunto de informaciones sobre fenómenos sociales $\mathrm{y}$ hechos que han estado tradicionalmente marginados de los currículos, sino que, desde su nueva perspectiva, deberá abarcar un vasto contenido de conocimientos, junto con una educación moral para poder hacer frente a las actitudes egoístas y oportunistas del mundo moderno. La educación en la democracia es una tarea encaminada al desarrollo de una personalidad que hace del diálogo, la confrontación de ideas y la participación de los elementos de su proceso formativo permanente. La educación necesita de aprendizajes innovadores que se abran a la problemática del mundo y preparen a las generaciones jóvenes para enfrentarlos de manera creativa y constructiva”25.

Si bien, continúa el autor, no existe un criterio unificador que nos permita identificar con claridad los componentes de la Educación para la Paz, los elementos que han sido resaltados son aquellos relacionados con los derechos humanos, desarme y medio ambiente. Finalmente quisiéramos señalar, a partir de los resultados que arroja el presente estudio, lo complejo que resulta en la práctica conectar dos esferas que hasta el momento se presentan como mundos aparte. Por un lado, la reflexión en filosofía política en materia de ciudadanía, derechos humanos, construcción de la democra-

25 www.monografías.com José Giovanni Alberola Ureña.

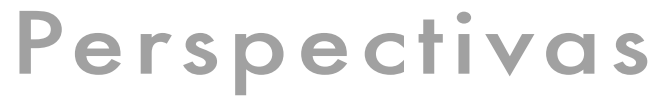


cia, fortalecimiento de la sociedad civil, donde las referencias son fundamentalmente europeas y norteamericanas y, por otra parte, la precaria realidad de nuestras democracias en América Latina, en particular la chilena.

¿Cómo hacer que la compleja y utópica cuestión de la ciudadanía -que implica no sólo la adhesión al principio de igualdad en materia de ejercicio de derechos sino que también, y principalmente, condiciones materiales concretas de acceso igualitario a oportunidades sociales y políticas que posibiliten este ejercicio- no se transforme en un asunto meramente conceptual, o en una aspiración que, por su imposibilidad de materialización a corto plazo, deba ser desechada?

\section{BIBLIOGRAFÍA}

- $\quad$ Aquín Nora; “Las Implicancias de la Categoría de Ciudadanía en la Intervención Profesional”. En Revista Confluencias. Córdoba, Argentina.Publicación del Colegio de Profesionales en Servicio Social de la Provincia de Córdoba, 1999.

- Borja, Jordi (2003) “La Ciudad Conquistada”, Alianza Editorial, S.A.

- $\quad$ Borja, J. y Castel m. (2004) “Local y Global: la gestión de las ciudades en la era de la información”, Taurus Editores. Madrid. Págs 17-18.

- Cortina, Adela: La Etica de la Sociedad Civil, Editorial Alauda ANAYA, 2002.

- Cortina, Adela: “Sociedad civil”, en Diez palabras claves en Filosofía Política. VD, Madrid, 1998.

- Cortina, Adela: "La Educación del Hombre y del Ciudadano”, Revista Iberoamericana de Educación, Número 7 - Enero Abril 1995, Biblioteca Virtual de la OEI.

- Gómez Alguacil Julio; “Los Desafíos del Nuevo Poder Local: La Participación Como Estrategia Relacional en el gobierno local”, www.revistapolis.cl 2005.

- Gómez Alguacil Julio: "La ciudadanía emergente y sus síntomas”, Madrid (España), marzo de 2002. http://habitat.aq.upm. es/boletin/n24/ajalg.html
¿Qué tipo de nuevas relaciones debieran establecerse entre actores del desarrollo sin pasar por alto el diagnóstico anterior?

¿Cómo garantizar condiciones de protección universales cuya defensa no se sustente en concepciones que no es posible sostener atendiendo al actual escenario, pero con plena vigencia en sus fundamentos ético/políticos?

¿Ha sido emprendida esta discusión en la sociedad chilena o aún estamos lejos de plantearnos cuestiones como las descritas?

¿Qué aspectos del modelo del Estado de Bienestar Conservador sería necesario revisar y cuáles debiesen ser mantenidos?

- Guimaraes Roberto, La ética de la sustentabililidad y la formulación de políticas de desarrollo en Ecología, política, naturaleza, sociedad y utopía. CLACSO 2002.

- $\quad$ Guimaraes Roberto; Tierra de sombras I y II, edición para Internet La insignia 2005.

- Escobar Juan, "Modelo económico, sustentabilidad y consumo", Revista Perspectivas Nº11,2002.

- Lechner, Norbert: “¿Por qué la Política ya no es lo que fue?” Revista Trimestral de la Fundación Foro Nacional por Colombia, № 29, Bogotá, Colombia, 1996.

- $\quad$ Lechner, Norbert: El Estado en el Contexto de la Modernidad, Seminario ONG cordillera, 2001

• Macassi, Sandro: “Las Agendas Públicas”, Calande, Mimeo 1996.

- Montagut Teresa, Política social. Una introducción. Arie Barcelona,2000.

- $\quad$ Nel-lo Oriol; Aquí no, conflictos territoriales en Cataluña. Ediciones Empuries 2004.

- $\quad$ Sabatini Francisco, Wormald Guillermo, "La Guerra de la Basura en Santiago, Desde el Derecho a la vivienda al derecho a la Ciudad” Revista Eures Volumen XXX.2004.

- Vecchio Benedetto, Entrevista a Robert Castel, documento en página web revisado noviembre 2005. 